Exercícios de autoinscrição no cinema:

o filme como experiência vivida pelo realizador

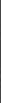

Henrique Codato

Eduardo dos Santos Oliveira

Breno Almeida Brito Reis

Artigo recebido em: 26/07/2019

Artigo aprovado em: 28/04/2020

D0I 10.5433/1984-7939.2019v15n27p190 


\title{
Exercícios de autoinscricão no cinema: o filme como experiência vivida pelo realizador
}

\author{
Self-inscription exercises in the cinema: \\ the movie as a lived experience through the director
}

\author{
Henrique Codato* \\ Eduardo dos Santos Oliveira* \\ Breno Almeida Brito Reis ${ }^{* * *}$
}

Resumo: Este trabalho pretende revisar a hipótese de JeanLouis Comolli formulada a partir da análise do filme Berlin 10/90, de Robert Kramer, sobre o engajamento corporal do realizador no espaço da cena exceder a representação em favor da experiência vivida. Busca-se apontar o caráter performativo da autoinscrição de Kramer, comparando-o com outros exercícios de autoinscrição a fim de demonstrar como esse regime ético-estético faz-se presente em distintos documentários contemporâneos.

Palavras-chave: Autoinscrição. Cinema. Performance. Berlin $10 / 90$.

\begin{abstract}
This paper intends to review the hypothesis of JeanLouis Comolli formulated from the analysis of Robert Kramer's work Berlin 10/90 about how the director's self-staging in the scene exceeds the representation in favor of the lived experience. We want to feature the performative character of Kramer's selfinscription in his film comparing it with other self-inscription exercises to demonstrate how this ethical-aesthetic regime is present in different contemporary documentaries.
\end{abstract}

\footnotetext{
* Doutor em Comunicação pela Universidade Federal de Minas Gerais. Professor do Programa de Pós-Graduação em Comunicação da Universidade Federal do Ceará e do curso de Cinema e Audiovisual da Universidade de Fortaleza (Unifor). ** Mestre em Comunicação pela Universidade Federal do Ceará. *** Mestrando em Comunicação pela Universidade Federal do Ceará.
} 
Keywords: Self-inscription. Cinema. Performance. Berlin $10 / 90$.

\section{Introdução}

Ao caracterizar o que denomina de "autocinema", Jean-Louis Comolli aponta um gradativo investimento subjetivo e íntimo de alguns cineastas em seus próprios filmes, culminando em estratégias de engajamento corporal direto, notadamente no cinema dito documentário, atravessado pela força do real (COMOLLI; SORREL, 2015, p. 66). Com efeito, o interesse da prática documentária pelo eu como categoria de alteridade contribuiu para o desenvolvimento de uma tendência de cinema centrada na expressão individual dos realizadores, que se dedicam a abordar questões de ordem pessoal, a registrar o cotidiano particular, a escrutinar suas relações identitárias e familiares e a inscrever-se no plano, colocando a vida em interseção com o cinema que fazem.

Neste artigo, gostaríamos de discorrer sobre o gesto da autoinscrição, termo referente à presença "visível e corporal" do realizador em seu filme (COMOLLI, 2008, p. 283). Em proximidade com as noções de corporalidade, presença e autoria, a autoinscrição remete à passagem física do realizador à cena filmada. De maneira a investigar a singularidade do corpo filmado do realizador - um sujeito tradicionalmente oculto atrás da câmera, agora a revelar-se em campo na postura de autor-ator -, atentamos ao desenvolvimento da auto-mise-en-scène de realizadores que deliberadamente se colocam ante a objetiva.

Embora o escopo da autoinscrição remonte à figura dos 
autores-atores do cinema burlesco ${ }^{1}$ (COMOLLI, 2008, p. 283), ela tem se relacionado, no contexto do cinema contemporâneo, a um regime performativo da imagem, em que se considera a cena como espaço de autopoiese do sujeito, no sentido de que "a vida se produz e se performa em dispositivos audiovisuais vocacionados à exposição da intimidade" (BRASIL, 2010, p. 191).

Nesse sentido, a proposta deste artigo é passar em revista as teorias de Comolli sobre o fenômeno da autoinscrição, tendo como referência seu ensaio $O$ Anti-Espectador: sobre quatro filmes mutantes, publicado originalmente em 2002 na revista Images Documentaires e compilado na coletânea Ver e Poder; e o verbete "Autocinema" do livro Cinéma: mode d'emploi, escrito em parceria com o documentarista e professor Vincent Sorrel. Em ambos os textos, Comolli descreve o paradigma da autoinscrição a partir da análise do filme Berlin 10/90 (1990), um autorretrato em planosequência do realizador Robert Kramer ${ }^{2}$. A esses apontamentos de Comolli, incorporamos a análise de dois outros filmes: La Lettre jamais écrite (1990), de Dominique Dubosc, e Solstice d'hiver (1990), de Gary Hill, que foram realizados sob condições similares 1 Comolli refere-se aos casos de Buster Keaton, Charles Chaplin, Jacques Tati e Jerry Lewis.

2 Ao longo de sua obra ensaística, Comolli (2008, p. 17) frequentemente alude ao plano-sequência de Kramer para sublinhar "a brecha que ele abre em cada um de seus espectadores e no corpo do cinema”. Berlin 10/90 é mencionado, além dos textos que utilizamos neste artigo, nos ensaios "Potências do vazio e plenos poderes" (2001); "Je ne sais pas bien mais quand même" (2004); "Les villes invisibles du cinéma" (2005); "L'oral et l'oracle: Séparation du corps et de la voix" (2006); "Passage à l'acteur" (2008); "L'acteur de passage: Esquisse d'une renaissance" (2009). 
às do filme de Kramer e também estão centrados no investimento corporal de seus respectivos realizadores.

Identificando nesses filmes as características da vertente pessoal e performativa no cinema contemporâneo, buscamos demonstrar como elas atestam as premissas de que o engajamento do corpo filmado do realizador no espaço da cena desenvolve uma "potência documental" cuja intensidade vem realçar a teia de relações da "inscrição verdadeira" - a "relação real de um tempo (aquele do registro), de um lugar (a cena), de um corpo (o ator) e de uma máquina (que assegura o registro)" (COMOLLI, 2008, p. 143) -, de modo que o filme seja testemunhado pelo espectador como uma experiência à qual o realizador se submete e pela qual se deixa afetar.

\section{Exercícios de Autoinscrição na Série Live}

Em 1990, em associação com o canal de televisão francês La Sept ${ }^{3}$, o realizador Philippe Grandrieux idealizou a série Live, convidando cineastas, fotógrafos e artistas visuais de diversas nacionalidades a realizar planos-sequência de uma hora, sem cortes ou pós-produção (COMOLLI, 2008, p. 285). O intuito do projeto foi resumido por Grandrieux (1999) da seguinte maneira:

Em Live, o que me interessava é a questão da duração, do fluxo, do continuum do tempo. Filmar um planosequência de uma hora é muito desestabilizador.

3 Criado em 1985, durante o governo de François Mitterrand, a Société d'Édition de Programmes de Télévision - La Sept foi um canal de televisão francês que tinha por missão ser um polo de produção e difusão da arte e da cultura européias. Em 1991, La Sept, La Cinq (France 5) e o canal alemão Arte Deutschland se fundem, originando o canal franco-alemão Arte. 
Pode-se construir qualquer coisa em dez minutos. Em 30 minutos, já se torna muito difícil ter a ideia de um começo, um meio e um fim, mas num plano-sequência de uma hora, acaba-se não sabendo o que filmamos, não há mais ponto de referência. Interessa-me ver o que acontece quando nos colocamos nessa situação de não saber. Colocamo-nos a filmar "o mundo que ocorre"; Live estava muito associado a essa frase de Wittgenstein no começo do Tractatus, que diz que "o mundo é tudo o que ocorre". ${ }^{4}$

Assim Grandrieux (1999) estabelece um limite temporal, o período de uma hora, a duração exata das fitas de vídeo Hi8 utilizadas nas gravações, e um modo de filmar, um plano-sequência e uma tomada ininterrupta, que despojam o realizador de seu posto de demiurgo, instaurando um princípio desestabilizador na roteirização do filme. Esse dispositivo calcado na duração prolongada tornase, então, uma espécie de desafio para o qual cada realizador desenvolveria seus próprios dispositivos de enfrentamento. Ao todo, foram realizados 14 planos-sequência na série $L i v e^{5}$, dentre os quais

4 Em entrevista para a revista Hors Champ, em 14 de outubro de 1999. No original: "Dans Live c'est la question de la durée, du flux, du continuum du temps qui m’intéressait. Tourner un plan séquence d'une heure est assez déstabilisant. On peut construire quelque chose en 10 minutes. En 30 minutes ça devient déjà assez difficile d'avoir une idée d'un commencement, d'un milieu et d'une fin, mais dans un plan séquence d'une heure on finit par ne plus savoir ce quon tourne, ne plus avoir de repère. Ça m'intéressait de voir ce qui se passe quand on se met dans cette situation de ne plus savoir. On se met à filmer "le monde qui arrive", Live était très lié à cette phrase de Wittgenstein au début de Tractatus qui dit que "le monde est tout ce qui arrive". (GRANDRIEUX, 1999).

5 São eles: Ainsi nous étions..., de Uri Korenhendler; Après la chasse, de Lasse Naukkarinen; Berlin 10/90, de Robert Kramer; Bernadette, de William Karel; C'est vrai, de Robert Franck; Dallas, Texas, de Ken Kobland; Histoires, de Philippe Grandrieux; L'Image Tampico, de Thierry Kuntzel; La Lettre jamais écrite, de Dominique Dubosc; Mon Angleterre jamais oubliée, de Nick Waplington; Place Rouge, de Daniele Incalcaterra; Salle de boxe, de Christian Argentino; Solstice 
destacamos aqui o plano-sequência de Robert Kramer, Berlin 10/90, considerado por Jean-Louis Comolli como exemplo paradigmático da autoinscrição no cinema.

Robert Kramer grava seu plano-sequência na tarde do dia 25 de outubro de 1990, das 15 h15 às 16 h15, no banheiro de seu apartamento em Berlim. A câmera, movendo-se em panorâmicas horizontais, ora enquadra um televisor que exibe planos filmados por Kramer nas semanas precedentes, ora enquadra uma cadeira em que o realizador eventualmente se senta para encarar a objetiva.

Comentando em voz off as imagens da Berlim recémunificada exibidas no televisor, ou falando diretamente à câmera enquanto corpo enquadrado, Kramer estabelece associações entre suas lembranças pessoais (sua condição de cineasta militante expatriado, a vida do pai em Berlim durante a década de 1930) e os contextos históricos que elas evocam (a reunificação alemã e o nazismo). Os detalhes filmados do Reichstag ${ }^{6}$, por exemplo, remetem Kramer ao incêndio do edifício em 1933, cujas chamas ele imagina que o pai tenha visto. As ruínas em Museumsinsel, a cinco minutos de onde o pai estudou medicina, são "as ruínas de muitos sonhos"; e as marcas de projéteis nos muros, para além de "traços da História", são "tiros no meu próprio corpo". Em suma, a capital alemã é, nas palavras de Kramer, o "cruzamento entre a história do mundo e meus fantasmas" e "a continuação de todos esses vestígios que remontam àquele passado, àquele passado codificado no meu corpo de maneiras que eu não poderia imaginar".

Há, portanto, um curto-circuito, entre "o extremo

d'hiver, de Gary Hill; e Visage Anthea, de Stephen Dwoskin.

6 Prédio do Parlamento Federal Alemão. 
singular" e "o comum plural" (COMOLLI; SORREL, 2016, p. 66), operação implicada no cerne da tendência autobiográfica no cinema documentário, algo que Michael Renov (2004) atribui ao desdobramento das políticas de identidade. Este nota que a autointerrogação do sujeito compõe-se em estreito diálogo com um panorama que o engloba e com figuras de alteridade próximas (a família, uma comunidade). Não ocorreria, desse modo, uma clausura egoísta, na medida em que há conexões, implícitas ou não, entre a expressão individual e microcosmos históricos, sociais, culturais.

O realizador francês Dominique Dubosc empreende um gesto convergente em seu plano-sequência La Lettre jamais écrite, ao conectar à ideia abstrata de paternidade a sua história pessoal, inspirado numa obra do fotógrafo estadunidense Duane Michals intitulada $A$ letter from my father. Trata-se de uma fotografia retratando o pai, o irmão e a mãe de Michals e que contém um texto manuscrito, em que o fotógrafo confessa ter sempre esperado uma carta que o pai, já falecido, prometera the escrever. A carta é o símbolo de uma manifestação de intimidade e afeto paterno que ele jamais experimentara e só poderia imaginar. Dubosc explica tudo isso, com o corpo no quadro, à sua madrasta Hisako. Ele projeta a situação de Michals em sua própria vida, com a intenção de que seu filme funcione à maneira de uma carta que ele, como filho, enviaria, por sua vez, ao próprio pai falecido, que era um estudioso da pintura oriental.

Dubosc grava o plano-sequência na casa que o pai construiu em Kamakura, no Japão, onde este passou os vinte últimos anos de vida e segmenta o continuum de tempo em "momentos", deslocandose entre os espaços da casa para rememorar, em cada um, alguma 
lembrança paterna. É um empreendimento descrito pelo realizador como "proustiano", na medida em que suas impressões derivam do acúmulo de memória dos objetos: de certos pormenores da casa, das fotografias de uma viagem que fizeram a Kyoto, de um filme em super-8 feito do pai no jardim, do túmulo dele etc. Há, portanto, uma profusão de elementos que Dubosc reúne para dar motor à filmagem.

De maneira similar, Kramer empenha-se, através da fala, em extrair das imagens que gravara de Berlim e de seu cotidiano as memórias ali incrustadas, percorrendo o que a cidade lhe evoca em nível tanto pessoal quanto histórico, de modo a esgotar a longa extensão do plano que está gravando. Para tanto, essas imagens exibidas no televisor seriam seu amparo, um dispositivo criado a partir de uma situação vivida na casa de amigos que, após uma reforma domiciliar, folheavam a biblioteca particular para se desfazer de alguns volumes, acessando assim as memórias encerradas naquelas páginas. À maneira daqueles livros, as imagens de Berlim funcionam como arquivo de memórias que se atualizam por meio da voz do diretor. Todavia, ainda à metade do plano-sequência, quem se exaure é o próprio Kramer, cuja fala logo se rarefaz. À medida que o tempo se inscreve no corpo do realizador, nele se estampa o cansaço.

Enquanto Dubosc aparentemente viola a regra estipulada por Grandrieux, desligando a câmera quando o itinerário doméstico que planejara encerra-se a poucos minutos de completar o tempo de filmagem previsto, Kramer mantém-se à mercê da longa duração que ainda se impõe. Encarando a câmera, ele se cala em longos silêncios, fecha os olhos, suspira. Sem saber exatamente o que fazer até atingir o fim da rodagem, ele confessa a dificuldade de falar e filmar simultaneamente, manifestando seu desconforto diante da 
"falsa fluidez" do tempo imposto.

Comolli sublinha que, ao "lograr a performance de filmar a si mesmo", Kramer atinge o ponto acentuado de uma gradativa "preocupação autobiográfica" no documentário, a partir da qual "os 'documentaristas' puseram-se a falar não somente em seu nome, mas de seu próprio nome, de sua vida, de sua família, de seus pais, para finalmente filmarem a si mesmos" (COMOLLI; SORREL, 2015, p. 65-66). A autoinscrição corporal, dentre essa variedade de gestos autorreflexivos, compreende-se sob a rubrica "autocinema", que designa a reconfiguração do autorretrato no domínio cinematográfico. Reconfigura-se porque, ao contrário de sua composição na pintura e na fotografia, o autorretrato filmado envolve uma nova variante: a duração, que "requer um relato" (COMOLLI; SORREL, 2015, p. 66). Em vista disso, a importância que Comolli confere a Berlin 10/90 talvez se deva ao fato de Kramer submeter seu próprio corpo à ação direta de uma duração hiperbólica. O tempo, como fator imperativo na relação entre câmera e corpo filmante-filmado, ali se adensa em sua extensão, enfatizando o embate entre o corpo facilmente exaurível e a máquina infatigável (COMOLLI, 2008, p. 286). É uma relação patente também no plano-sequência do artista visual Gary Hill, intitulado Solstice d'hiver.

Colocando o corpo no quadro, Hill cria uma estratégia de desaceleração corporal ao confrontar-se com a duração do planosequência. Igualmente recluso no espaço doméstico, ele infunde a lentidão no próprio corpo - e, consequentemente, em seu manejo de câmera -, iniciando a filmagem com uma panorâmica de $360^{\circ}$ que perscruta muito vagarosamente a sala de estar de seu apartamento em Seattle, Washington. No decorrer da panorâmica, a câmera se 
detém sobre uma vitrola. O realizador então entra em quadro, caminha de forma extremamente lenta até o aparelho e põe um disco para tocar - em que se ouve a obra I am sitting in a room, trabalho de arte sonora do compositor estadunidense Alvin Lucier. Quando a câmera completa seu giro, já se passou meia hora. Hill reaparece em quadro, caminhando lentamente em direção ao banheiro. A câmera permanece na sala, enquanto ouvimos o barulho do chuveiro, até que o realizador ressurge nu, ainda em ritmo vagaroso. No entanto, ao tomar a câmera em mãos, o corpo de Hill se acelera subitamente. Ele arranca a máquina de seu suporte e a leva consigo aos outros cômodos do apartamento. Depois de gravar-se lavando bruscamente os utensílios na pia da cozinha, segue para o quarto. Ali a câmera enquadra a cama, sobre a qual Hill atira seus livros - dos quais ele lê curtos trechos - e suas roupas, até que a duração se encerra.

Centrando-se na cerimonialização corporal ativada por suas mudanças de ritmo, Solstice d'hiver apresenta reconhecível caráter performativo, considerando-se a carreira de Gary Hill no campo da videoarte e seus trabalhos autorreferentes ${ }^{7}$. Filmar-se, fazendo do próprio corpo o protagonista de uma performance endereçada à câmera, é um procedimento comum na videoarte, razão pela qual foi associada à "estética do narcisismo", como assinalou a crítica Rosalind Krauss (2008). Com efeito, uma vez que as novidades técnicas do dispositivo eletrônico facilitavam a realização individual e a autoinscrição do corpo, Raymond Bellour (1988, p. 327) identificara nos autorretratos de videoartistas as apropriações

7 Hill tem diversos trabalhos no campo da videoarte e da videoinstalação em que filma o próprio corpo. Entre eles, destacam-se Up against down (2008), Impressions d'Afrique (2003), Namesake (1999) e Switchblade (1989). 
subjetivas que balizaram a entrada das formas audiovisuais no espaço autobiográfico e que abriram horizonte para a expressão dos realizadores no âmbito íntimo e experimental. Tais aspectos sem dúvida refletem-se na tendência autobiográfica do cinema documentário, já que as estéticas videográficas se disseminaram transversalmente, promovendo "passagens", interlocuções técnicas, políticas e estéticas nos campos de criação de imagens.

Ultrapassando sua utilização como suporte, o meio eletrônico veio fazer da filmagem processo análogo ao pensamento, sobretudo como ferramenta de reflexão sobre a cultura audiovisual, como explica Philippe Dubois. Os cineastas que passaram a experimentar esse "estado-vídeo", a partir dos anos 1980, o utilizavam como "um meio privilegiado de refletir (sobre) o (seu) próprio cinema", como "o instrumento de expressão quase específico de uma análise, de uma interrogação, de uma investigação pessoal, de um questionamento dos cineastas em torno e no coração de sua arte" (DUBOIS, 2004, p. 131). Entre tais cineastas estão Alain Cavalier, Chantal Akerman, Jean-Luc Godard, que ocasionalmente inscreveram o próprio corpo em suas obras autorreferenciais, e cuja atuação entre cinema, vídeo, ficção e documentário os faz figurar como exemplos expressivos da tendência autobiográfica no documentário, nesse contexto de passagens. Aí também pode-se incluir Kramer, que teve contato "com o cinema de autor, com o cinema experimental e com a videoarte" em sua formação como cineasta e empreendeu experimentos autorreferenciais com o meio eletrônico, realizando filmes de considerável importância crítica em formatos de vídeo não-profissional - o VHS e o Hi-8 -, como é o caso de Berlin 10/90 (LA FERLA, 2008, p. 143). 
Note-se que o projeto Live propõe uma mesma diretriz - o exercício do plano sequência - à artistas cujas trajetórias interseccionam as diversas áreas de criação centradas na imagemcâmera. Por isso, desenvolver o gesto cinematográfico numa extensão longa e contínua do tempo - um exercício de dilatação da inscrição verdadeira - é o ponto nodal que permite aproximar o trabalho de Kramer, documentarista, e de Hill, videoartista; e este paralelo comparativo se justifica, ademais, e sobretudo, pelo fato de que ambos decidem inscrever o tempo no próprio corpo.

\section{Corpo, Performance e Autoinscrição}

No ensaio $O$ Anti-Espectador, Comolli observa que no cinema documentário os realizadores vinham investindo o próprio corpo, “e, às vezes, a intimidade”, em seus filmes, enquadrando-se, interpretando a si mesmos. À revelia das motivações individuais que instigassem essas filmagens de si, a autoinscrição corporal do realizador, de acordo com Comolli, guarda uma "dimensão documentária" que sequer os véus de denegação ${ }^{8}$ ficcionais poderiam anular. Pois a presença "visível e corporal" do cineasta funda um "círculo de autorreferência" entre filme e corpo filmado, acentuando as relações em jogo no ato de criação. Os vínculos "entre identidade e subjetividade, entre corpo, fala, personagem consciente e inconsciente, ritmo, energia, cansaço..." articulam-se tão "indissolúveis" que tornam a pessoa filmada "um novo objeto de conhecimento" (COMOLLI, 2008, p. 283).

8 Para Comolli (2008), o lugar do espectador de cinema na experiência do filme oscila entre a crença e a dúvida, num exercício de denegação: crer sem deixar de duvidar, duvidar sem deixar de crer. 
Comolli alerta que essas teias de relações subjetivosomáticas amplificadas pelo cinema veem-se enfraquecidas diante de sua cooptação pelo "devir-espetáculo do mundo"; isto é, diante de sua contaminação pelas cenas confeccionadas e veiculadas pelas mídias conforme a retórica iterativa e persuasiva da propaganda e da televisão, que exortam a credibilidade de seus "fatos de discurso" como a realidade última, regulando ou mesmo suplantando a experiência subjetiva de mundo. Como exemplo, Comolli conta o anedótico caso de um vilarejo alsaciano em que a violência urbana parecia aos moradores algo mais perceptível nos informes telejornalísticos do que nas ruas. O "devir-espetáculo" opera, pois, no sentido oposto ao reforço da dimensão ética que o cinema instaura a partir de seu núcleo documentário. Diante disso, Comolli considera que compete ao cinema resgatar sua "garantia documentária", uma garantia que mesmo o cinema dito documentário precisa reassegurar, para afirmar sua incongruência com as dissimuladas quimeras midiáticas. Esta garantia baseia-se na asserção do caráter afetivo da relação com a pessoa filmada, algo que se ressalta de forma mais intensa, justamente, nas situações de investimento corporal do realizador:

A fórmula dessa garantia documentária baseiase em algumas condições simples: 1. que o ator e o personagem formem apenas um; 2. que o liame corpo-fala-sujeito-experiência-vida seja assegurado ao ponto de a experiência da filmagem não poder não afetar o corpo filmado; e 3. que o filme seja, com efeito, o documento dessa afetação. É nesse sentido que poderíamos dizer que o documento último, o nec plus ultra do documentário, é o corpo filmado do cineasta ${ }^{9}$, que de alguma forma curto-circuita $\mathrm{o}$

9 Grifo nosso. 
círculo da representação, fazendo confundir sujeito e objeto, meios e fins, prova e experiência. A entrada em cena do corpo do autor amplifica o conjunto corpo-fala-sujeito-experiência-vida para torná-lo ainda menos "falsificável": filmando a si mesmo, o autor garante por meio de sua pessoa a potência dessa confusão que constitui toda a singularidade do cinema documentário. O corpo filmado do cineasta impõe uma prova a mais da essência documentária do filme, capaz de produzir um efeito de verdade sobre o qual não haveria mais o que discutir. (COMOLLI, 2008, p. 285)

A performance de Kramer diante da câmera em Berlin 10/90, ao evidenciar de forma tão contundente o elã corpo-falasujeito-experiência-vida, provoca um deslocamento no lugar espectatorial, demarcando, como "filme mutante", o que Comolli (2008, p. 285) considera uma nova configuração de documentário. O engajamento radical do corpo filmado, ao impossibilitar a ficção e o simulacro, destituiria o espectador de sua capacidade de projeção no círculo de representação para colocá-lo no posto "insuportável” de "vigilante" do jogo fílmico e dos corpos ali implicados (COMOLLI, 2008, p. 288). Em Berlin 10/90, estamos nessa desconfortável e sádica posição como cúmplices do dispositivo que esgota Kramer progressivamente. Podemos apenas assistir àquilo que ocorre à pessoa filmada na circunstância da tomada ${ }^{10}$ e observar "como o filme afeta aquela ou aquele que é filmado" (COMOLLI, 2008, p. $305)$.

10 A circunstância da tomada, como descreve Fernão Pessoa Ramos (2013, p. 132-133), "instaura a abertura fenomenológica da imagem-câmera com as formas de vida e sua duração, conforme experimentadas pelo sujeito, a partir de seu corpo, em interação com a exterioridade que chamamos mundo". 
$\mathrm{Na}$ nova distribuição de cartas que se oferece ao espectador, espera-se que a experiência do filme seja vivida como uma prova não mais, de início, pelo espectador (ficção, representação), mas, antes, por aquele ou aqueles que são filmados (ao mesmo tempo atores e personagens); que eles sejam afetados por essa prova no próprio curso da experiência filmada, e que o que eu devo compartilhar com eles seja esse rasgo no véu da representação: partilha de uma perda da ficção, de um efeito de real que abre uma brecha na cena. (COMOLLI, 2008, p. 290)

Comolli nos oferece, assim, uma perspectiva de análise fílmica aplicável às filmagens de si, a partir da qual consideramos o filme como uma experiência desencadeada pelas circunstâncias da filmagem e vivida pelo corpo filmado. Atente-se que o valor de documento do filme refere-se não a sua instrumentalização comprobatória de situações alheias ao gesto cinematográfico, mas à cinegenia $^{11}$ da experiência, à experiência catalisada pela filmagem. A relação entre dispositivo e experiência, discutida na formulação do conceito de "imagem-experiência" por Cezar Migliorin, pode nos ajudar a desenvolver uma mirada analítica sobre esses processos na autoinscrição corporal dos realizadores.

Migliorin (2008, p. 113-114) retoma o conceito de experiência em sua acepção foucaltiana: como processo de transformação do indivíduo diante de relações com o indeterminado, e, consequentemente, como instância de resistência aos poderes. Como explica o filósofo Peter Pál Pelbart, Foucault concebia seu próprio método de escrita como um processo de transformação

11 Propomos pensar a cinegenia como uma qualidade estética própria do cinema, que ao captar a aparência de um objeto, faz dele emergir algo que se encontra para além da realidade e da materialidade por ela reveladas. 
pessoal que se concatenava em "livros-experiência", expressão pela qual compreendemos a obra como a processualidade de uma experiência que afeta o artista:

Todo o desafio está em conciliar o fato de que um livro parte de uma experiência pessoal, mas não constitui o relato dessa experiência, já que o livro é em si mesmo uma experiência em um sentido mais radical, a saber, uma transformação de si, e não a reprodução da experiência vivida "tal como ela ocorreu" e que estaria na origem dessa escrita, nem sua transposição direta. (PELBART, 2013, p. 209, grifo do autor)

Influenciado por filósofos como Friedrich Nietzsche, Georges Bataille e Maurice Blanchot, Foucault compreende a experiência "como uma metamorfose, uma transformação na relação com as coisas, com os outros, consigo mesmo, com a verdade" (PELBART, 2013, p. 207). Nessa linhagem de pensamento, frisa-se que o conceito de experiência diverge substancialmente da acepção fenomenológica do termo, segundo a qual a experiência constitui-se como processos de reflexão que visam constatações e desembocam na localização de um "sujeito fundador". Para Foucault, a experiência designa o processo em que o indivíduo põe sua existência em relação radical com uma variedade de forças e categorias oblíquas para compor-se e recompor-se, visando atingir, na vida, o "invivível" (MIGLIORIN, 2008, p. 114). Algo comparável ao processo arriscado que a prática documentária apresenta aos realizadores diante do "real": "lacunas ou contornos que logo nos são dados para que os sintamos, os experimentemos, os pensemos" (COMOLLI, 2008, p. 177). 
Nessa perspectiva, Migliorin discorre sobre a experiência do corpo filmado remontando às relações estabelecidas com o dispositivo de filmagem. O dispositivo, como estratégia de nãocontrole na relação filmada, ativa a experiência como o que afeta os corpos por provocar o que lhes arrouba como involuntário, impensado e imprevisto. Por basear-se na interlocução de ignorâncias recíprocas, este procedimento não parece tão complexo na relação filmada interpessoal, no que há de indecifrável entre pessoa filmada e realizador, como esfinges que se defrontam. Mas, como pode o corpo que se filma (como é o caso de Kramer) desenvolver um campo de instabilidade consigo mesmo?

A questão é compreender que o corpo sozinho, interpelando a si, possui um germe de não-controle que, confrontado com o absconso da máquina, com o tempo que ela lhe injeta e com os dispositivos de abertura ao real, o faz entrar em relação com o impensado de si. Filmado e filmante, o corpo seria uma incógnita a si mesmo. A auto-mise-en-scène, como define Comolli, caracterizase por essas "iniciativas não conscientes que são testemunho de uma relação direta entre corpos e olhares, ou corpos e máquinas, mais além das consciências que atuam, organizam ou ordenam" (COMOLLI; SORREL, 2015, p. 65). Quando o corpo se filma, o "impensado da máquina" vem desmontar o que o corpo poderia calcular, assim como a "indisciplina" do corpo desarticula os poderes já inculcados na máquina cinematográfica. $\mathrm{O}$ dispositivo que o corpo aplica sobre si, ainda que planejado por ele mesmo, possui brechas; e é por tais lacunas que a experiência ocorre, arrebatando o que se poderia prever: 
Há nesse instante, no interior do dispositivo a invenção de um campo de experiência. Ele é separado da vida? Sim e não. Claro, a vida não é um livro, nem o dispositivo dos realizadores que trabalhamos se confunde com a normalidade cotidiana - por mais que em alguns casos se aproxime. Há um filme que está sendo feito, há uma imagem sendo procurada. No interior desses dispositivos entra-se em estado de possibilidade de experiência. A criação desse dispositivo se faz com a vida, com o tempo que corre durante uma viagem, com o tempo e espaço que se compartilha com o filho e com a família, com o espaço que se constrói em uma relação amorosa (No Sex Last Night (1992), de Sophie Calle), com o tempo que se gasta resolvendo um problema burocrático (Sandra Kogut) ${ }^{12}$. (MIGLIORIN, 2008, p. 132-133, grifo do autor)

Que o corpo seja incontornavelmente afetado pela experiência do filme demonstra a conjunção, imanente às circunstâncias de filmagem, entre cena e vida. A experiência excede a representação, diz-nos Migliorin. A "verdade dos corpos", sua vulnerabilidade às situações desencadeadas pelo dispositivo, é por demais potente para sustentar denegações, por isso Comolli alega a "impossibilidade de simulacro". Mas, se assistimos ao corpo sofrer a experiência, também percebemos que ele é um dos agentes responsáveis por desencadeá-la. Neste quesito, há uma conotação performática relativa à relação engendrada entre o corpo e a câmera, pois aí se enseja, como propõe Comolli, a tensão somático-maquínica constituída pela performance desse corpo - sua atuação de presença, suas atitudes - diante da máquina, que também atua, por sua vez, sobre o corpo abordado.

12 Alusão ao filme Passaporte Húngaro (2001), de Sandra Kogut. 
Em função do imbricamento entre o corporal e o fílmico no gesto de Kramer, revela-se importante, neste momento do texto, produzir uma zona epistemológica de friç̧ão e interferência entre o campo do cinema e os estudos da performance. A nosso ver, o corpo filmado por si mesmo reforça a dimensão performativa reminiscente da autoexploração corporal da performance art, cujos princípios foram aliados ao gesto cinematográfico pelos videoartistas que passaram a montar a câmera sobre si e utilizar a filmagem como catalisador de tensionamentos exploratórios do próprio corpo e de seus limites, "limite do suportável, do tolerável, do tédio, da dor, da provocação" (PARFAIT, 2001, p. 179) - algo que reverbera no plano-sequência de Kramer.

Assim, desfazendo a noção de "objeto" previamente formado, inteiro e fechado em si mesmo, o corpo filmante-filmado desordena as prerrogativas de figuração comumente relacionadas à arte representacional. No regime da mimese, ao contrário do que acontece no filme de Kramer ou na obra de Hill, a condição de existência dos seres e das coisas é tomada unicamente a partir de sua dimensão concreta. Como indica Luiz Rezende (2013), essa suposição implícita conduzida pela acepção de representação não decorre apenas de uma indeterminação terminológica, mas porque se toma, frequentemente, a virtualidade dos seres e objetos como parte de suas materialidades e "realidades" já dadas e constituídas. Segundo o autor, um documentário não é feito apenas com a dimensão real dos objetos-temas de documentaristas, mas com as suas virtualidades: "a memória de seus personagens ou testemunhas, a sobrevivência de um passado no presente, a indeterminação da ação-reação dos indivíduos participantes, etc.” (REZENDE, 2013, p. 9). 
Nesse sentido, aqui, o regime da mimese vê-se substituído por uma perspectiva que tenta ressaltar determinados elementos inviabilizados quando o ponto de partida analítico deriva da associação compulsória do documentário a uma noção de realidade atrelada à existência tangível e pré-concebida das coisas. Ter conhecimento disso nos auxilia a compreender as relações que alguns conceitos da performance podem estabelecer com as imagens fabricadas pelos realizadores na medida em que apontam para problematizações do corpo para além da linguagem e não para condições preexistentes. No caso do cinema autorreferente de Kramer, mais especificamente a partir do gesto de confrontar-se com a objetiva, tomamos a dimensão performativa a partir interação entre dois pares complementares: corpo e câmera (no espaço da mise-en-scène) e montagem e espectador (na experiência do filme).

A câmera, na condição de máquina que dispara modulações e acasos que se atualizariam de outra forma caso não houvesse filmagem, faz com que o corpo filmado do cineasta, em sua potência performativa, confunda-se entre sujeito e objeto e seja rigorosamente afetado pela experiência de filmagem, atualizando-se na (e com a) imagem. Em Berlin 10/90, Kramer confronta-se com a câmera, entabulando uma performance confessional que, em tensão com o dispositivo autoinflingido, se difrata em experiência de esgotamento. Como diz Comolli, (2008, p. 288, grifo do autor) "o filme é afetado por seu próprio sistema, e é o corpo do cineasta que nos oferece o documento dessa lenta decomposição". O cansaço, como atitude cotidiana, assinala a emergência do impensado ao próprio corpo, revelando a atuação progressiva da câmera, da duração que ela injeta no corpo. Kramer reconhece sua desorientação citando, em suas confissões à 
câmera, uma passagem do Tractatus Logico-Philosophicus (1921), do filósofo austríaco Ludwig Wittgenstein - obra que serviu igualmente de inspiração a Grandrieux para idealizar o projeto Live: "Se escrevesse um livro: $O$ mundo tal como encontro, deveria reportar-me a meu corpo e dizer quais membros estão sob minha vontade e quais não estão, etc" (WITTGENSTEIN, 1968, p. 111).

Podemos assistir a uma situação similar de desorientação corporal, conforme se depreende da descrição de Noël Burch, no filme Chelsea Girls (1966), de Paul Morrissey e Andy Warhol. Chelsea Girls é composto por doze planos-sequência de aproximadamente 30 minutos ${ }^{13}$ cada, a duração correspondente à extensão-limite dos chassis utilizados nas filmagens (BURCH, 2008, p. 144). A dilatação dainscrição verdadeira se impõe e sua tensãoéenfatizadaao espectador no plano-sequência intitulado Pope Ondine, quando a infusão do tempo no corpo desestabiliza Ondine, o ator que protagoniza a cena. Quando a gravação se inicia, Ondine pergunta se já estão filmando, se está falando alto o suficiente, e injeta anfetamina no pulso com uma seringa. Sua desorientação evidencia-se no diálogo entabulado com o realizador Paul Morrisey, que está fora de campo: "Acho que não consigo dizer nada. Acho que não consigo". Mas logo ele desenvolve um monólogo incorporando uma figura pontifical, Pope Ondine, semelhante a sua performance em outro plano-sequência de Chelsea Girls, intitulado Father Ondine and Ingrid. Ainda interpelando quem está fora de campo, Ondine demanda a confissão de uma moça, Ronna Page, que então aparece em quadro. No meio de um diálogo absurdo em que Ondine sugere que Ronna transe com

13 Os planos-sequência de Chelsea Girls são projetados simultaneamente em dupla e justapostos. 
Jesus Cristo, ela o acusa de impostor e eles se desentendem. Ondine agride Ronna verbal e fisicamente, expulsando-a dali. Furioso, ele ameaça abandonar a cena, mas a equipe o faz permanecer. Ondine continua a resmungar sobre o ocorrido, mas sua histeria logo dá lugar ao esgotamento corporal provocado pela duração. Entediado, sem saber o que fazer, ele reiteradamente checa se a tomada (e seu "suplício") está perto de acabar (BURCH, 2008, p. 144).

A tomada longa e ininterrupta, de acordo com Burch, faz a câmera atuar como "torturadora", infligindo seu bloco de tempo sobre o corpo filmado e difratando sua performance. Experiência análoga à de Kramer: "a duração e a dureza da filmagem como experiência vivida, ou melhor, sofrida, pelo corpo filmado" (COMOLLI, 2008, p. 286). A desorientação de Kramer pode ilustrar o ponto em que "uma prática de si tangencia uma zona de não conhecimento ou de dessubjetivação, onde um sujeito assiste ao seu colapso ou roça sua dessubjetivação" (PELBART, 2013, p. 228). Neste ponto, percebemos a incapacidade do corpo filmado de isentar-se da experiência e a incapacidade de controlá-la, ainda que ele tenha parte em elaborar o dispositivo que a engatilha. Daí é possível examinar os documentários pessoais como manifestação emblemática de práticas ético-estéticas que os realizadores vêm empregando para afetar a própria existência, como um processo de autopoiese e resistência - o que nos remete, novamente, a Foucault e a sua concepção do "sujeito ético":

O sujeito ético dirige-se, investe, modela à sua maneira, com o seu estilo, aquela parte de si que não se deixou afetar pelos códigos normativos, que não se dobrou a eles, que se indispôs ou manteve uma não disponibilidade. Relação consigo, portanto, autorreferência e não mais referência 
a um social. Relativiza-se, desse modo, o peso incontornável de um social coercitivo, abrindose o campo às sociabilidades lúdicas, inventivas e criativas, indiferentes aos imperativos identitários. (TEIXEIRA, 2012, p. 95)

Eis como a autorreferencialidade, que passamos a compreender em consonância com a concepção foucaultiana de "cultura de si", constitui ponto de resistência aos poderes como uma "estética da existência": quando os indivíduos criam modos de subjetivação no cotidiano, fazendo da existência um campo de experimentações ético-estéticas como maneira de agir no mundo. Formas de vida que inventam a si mesmas e se insurgem. As condutas pessoais irradiam-se, a partir da esfera cotidiana dos indivíduos, como vetores de intervenção política no mundo.

\section{Conclusão}

$\mathrm{O}$ trajeto que percorremos até aqui e a intersecção que buscamos produzir entre o campo do cinema e os estudos da performance, passando pela obra de diversos cineastas e videoartistas, nos parece uma composição pertinente para pensarmos o corpo inserido em esferas de investigação subjetiva que questionam o regime da mimese como única forma de acesso e produção de arte. Conforme tentamos mostrar, os endereçamentos de Robert Kramer e de Gary Hill à câmera representam uma síntese formal da autoinscrição. Neles, há uma espécie de continuidade entre o corpo do cineasta inscrito na imagem, a forma do filme (que se modula a partir das afetações que a relação corpo-câmera estabelece) e o espectador 
(que, como instância do olhar, se deixa também afetar). O efeito de distanciamento que o engajamento corporal dos realizadores provoca no círculo da representação invoca no espectador contemporâneo uma postura crítica ativa diante dos processos fílmicos e das relações subjetivas que se desencadeiam durante a tomada.

As formulações teóricas de Comolli acerca do fenômeno da autoinscrição permitem abordar o cinema pessoal a partir do confronto entre máquina e corpo, e dos jogos de poder que ambos articulam e desarticulam na relação filmada. Nesse sentido, norteia-se uma perspectiva analítica cuja necessidade Philippe Lejeune (2013) apontava: a de pensar os filmes pessoais sob a lógica específica do cinema, evitando subordiná-los aos pressupostos puramente linguísticos da enunciação do eu ou ao referencial da tradição literária da autobiografia.

Em adição, as confissões de Kramer à câmera e o périplo de Dominique Dubosc pela casa do pai, postos em comparação, evidenciam como suas estratégias de auto-mise-en-scène apresentam características marcantes dos filmes pessoais: a realização autárquica, doméstica, artesanal; a autorreferencialidade; o dispositivo fílmico aberto às contingências; e, acima de tudo, o cruzamento ético-estético que aglutina cena e vida - o que se pode observar nas obras de outros realizadores que Comolli e Sorrel $(2015$, p. 66) incluem sob a rubrica de "autocinema", "começando por Jonas Mekas, Naomi Kawase, Boris Lehman, Stephen Dwoskin, Dominique Cabrera, Chantal Akerman, sem esquecer o cineasta israelense David Perlov", bem como em projetos de Agnès Varda, Alain Cavalier, Avi Mograbi, entre tantos outros. 


\section{Referências}

BELLOUR, Raymond. Autoportraits. Communications, Paris, $\mathrm{n}$. 48, p. 327-387, 1988. [article]. Fait partie d'un numéro thématique: Vidéo.

BRASIL, André. Formas de vida na imagem: da indeterminação à inconstância. Revista FAMECOS, Porto Alegre, RS, v. 17, n. 3, p. 190-198, set. /dez. 2010.

BURCH, Noel. Práxis do cinema. São Paulo: Perspectiva, 2008. 232p.

COMOLLI, Jean-Louis. Ver e poder: a inocência perdida: cinema, televisão, ficção, documentário. Belo Horizonte: Editora UFMG, 2008. 373p.

COMOLLI, Jean-Louis; SORREL, Vincent. Cine, modo de empleo. Tradução de Margarita Martínez. Ciudad Autónoma de Buenos Aires: Manantial, 2015. 395 p.

DUBOIS, Philippe. Cinema, vídeo, Godard. Tradução de Mateus Araújo Silva. São Paulo: Cosac Naify, 2004. 323p.

FOUCAULT, Michael. História da sexualidade, 3: o cuidado de si. Tradução de Maria Thereza da Costa Albuquerque. Revisão técnica de José Augusto Guilhon Albuquerque. Rio de Janeiro: Edições Graal, 1985. 320p.

GRANDRIEUX, Philippe. Au commencement était la nuit: entretien avec Philippe Grandrieux. [Entrevista concedida a] Nicolas Renaud, Steve Rioux e Nicolas L. Rutigliano. Hors Champ, Montréal, Canadá, 14 oct. 1999. versão online. Disponível em: http://www.horschamp.qc.ca/Emulsions/grandrieux.html. Acesso em: 10 fev. 2018. 
KRAUSS, Rosalind. Vídeo, a estética do narcisismo. Arte $\&$ Ensaios, Rio de Janeiro, RJ, n. 16, p. 144-157, jul. 2008.

LA FERLA, J. Robert Kramer: técnica, paixão e ideologia. Devires, Belo Horizonte, MG, v. 5, n. 2, p. 136-155, 2008. Disponível em: http://www.fafich.ufmg.br/devires/index.php/ Devires/article/view/310/171. Acesso em: 17 fev. 2018.

LEJEUNE, Phillipe. Cinema e autobiografia: problemas de vocabulário. In: LEJEUNE, Phillipe; NORONHA, Jovita Maria Gernheim (org.). O pacto autobiográfico: de Rousseau à internet. Tradução de Jovita Maria Gernheim Noronha e Maria Inês Coimbra Guedes. Belo Horizonte: Editora UFMG, 2014. p. 257-274.

\section{MIGLIORIN, Cezar Ávila. Eu sou aquele que está de}

saída: dispositivo, experiência e biopolítica no documentário contemporâneo. 2008. 213 f. Tese (Doutorado em Comunicação) Universidade Federal do Rio de Janeiro, Rio de Janeiro, 2008.

PARFAIT, Françoise. Vidéo: un art contemporain. Paris: Éditions du Regard, 2001. 214p.

PELBART, Peter Pal. O avesso do niilismo: cartografias do esgotamento. São Paulo: N-1 Edições, 2013. 448p.

RAMOS, Fernão Pessoa. Mas afinal... o que é mesmo documentário? São Paulo: Senac, 2013. 448p.

RENOV, Michael. The subject of documentary. Minnesota: University of Minnesota, 2004. 286p.

REZENDE, Luiz Augusto Microfísica do documentário: ensaio sobre criação e ontologia do documentário. Rio de Janeiro: Beco do Azougue, 2013. 276p.

TEIXEIRA, Francisco Elinaldo. Cinemas "não-narrativos": 
experimental e documentário - Passagens. São Paulo: Alameda, 2012.327p.

WITTGENSTEIN, Ludwig. Tractatus logico-philosophicus.

Tradução de José Arthur Giannotti. São Paulo: Edusp, 1968. 28p. 